\title{
PAGET'S DISEASE OF THE NIPPLE
}

\section{ON PAGET'S DISEASE OF THE NIPPLE.}

\author{
BY W. SAMPSON HANDLEY, LONDON.
}

(From the Bland-Sutton Pathological Institute of the Middlesex Hospital.)

THere is probably no disease of equal rarity which has given rise to such divergence of opinion or gathered round itself such a mass of literature as Paget's disease of the nipple. Deaver, McFarland, and Herman' ${ }^{1}$ give references to 197 papers dealing with it. The subject has interested me for a Iong period. In my unpublished Astley Cooper Prize Essay of 1904 I put forward a tentative theory of the disease, which the slow accumulation of material through succeeding years has enabled me to test, and I think to prove.

After dealing with lymphatic obstruction, the result of permeation, I went on to say, in 1904:

In connection with the subject of cancerous pachydermia it may be remarked that very probably Paget's disease of the nipple is an example of this condition, and that the eczematous thickened condition of the nipple is not the precursor, but the result, of subjacent cancer commencing near the nipple.*

It is quite possible that a cancerous growth might be present for years without forming a palpable lump, especially considering that the form of cancer which is found in Paget's disease is slow of growth and not prone to affect the glands.

In Paget's disease, however, the pachydermatous condition seems to partake more of an inflammatory nature, and is not due simply to lymphatic obstruction. Possibly this is owing to the irritant character of the discharge of the nipple which is so often present. Ziegler describes an inflammatory form of pachydermia as well as the form due simply to lymphatic obstruction. In the former variety the dermis shows aggregations of cells akin to granulation tissue, and the lymphatics and the tissues around them are crammed with lymphoid cells.

Barling ${ }^{2}$ records a case of Paget's disease in which the malignant growth was situated some distance from the nipple. The patient, a lady, age 58, had for six months suffered from intractable eczema of the left nipple, the areola being unaffected. 'The nipple felt thick and leathery ; it was abraded, but not ulcerated. On the abraded surface was some sticky discharge. Running directly inwards from the nipple was an indurated cord $1 \frac{1}{2}$ in. long, which ended in a nodule the size of a horse-bean in the substance of the breast.

Microseopically the nipple showed almost complete absence of the horny layer of the epidermis, with great thickening of the rete mucosum. The latter was obscured by small-celled infiltration which extended into the corium. There were some patches which appeared to be due to overgrowth of the sebaceous glands. The milk-ducts were full of epithelium, surrounded by hyaline connective tissue, and in places by small-celled infiltration. At one point a small patch of alveolar carcinoma was seen.

A section of the breast nodule showed it to be acinous carcinoma, though in places attempts at the formation of duct carcinoma appear. Barling concludes that, as the result of the eczema, a cancerous process started in the ducts and extended thence to the acini.

Is it not at least equally likely that the primary disease was the acinous carcinoma, which permeated the lymphatic plexus of the nipple, $\dagger$ and in doing so obstructed return of lymph from it; and that in consequence a pachydermia of the nipple was produced which led to compression and obstruction of the milk-ducts?

I have not been able to secure any material for the microscopical investigation of Paget's disease. For the present, therefore, the above theory of its pathology remains unproved. All that can be said is that the explanation given brings Paget's disease uncer the general laws of cancer, instead of leaving it as a mysterious entity standing by itself.

* The view that carcinoma is the precursor of Paget's disease was first advanced by Dr. George Thin, Brit. Med. Jour., May 14, 1881.

+ Barling's original view as to the origin of the growth in the ducts harmonizes better with Sir Lenthal Cheatle's recent work. Cheatle has shown that most cancers of the breast are of duct origin.

VOL. VII.-NO, 26. 


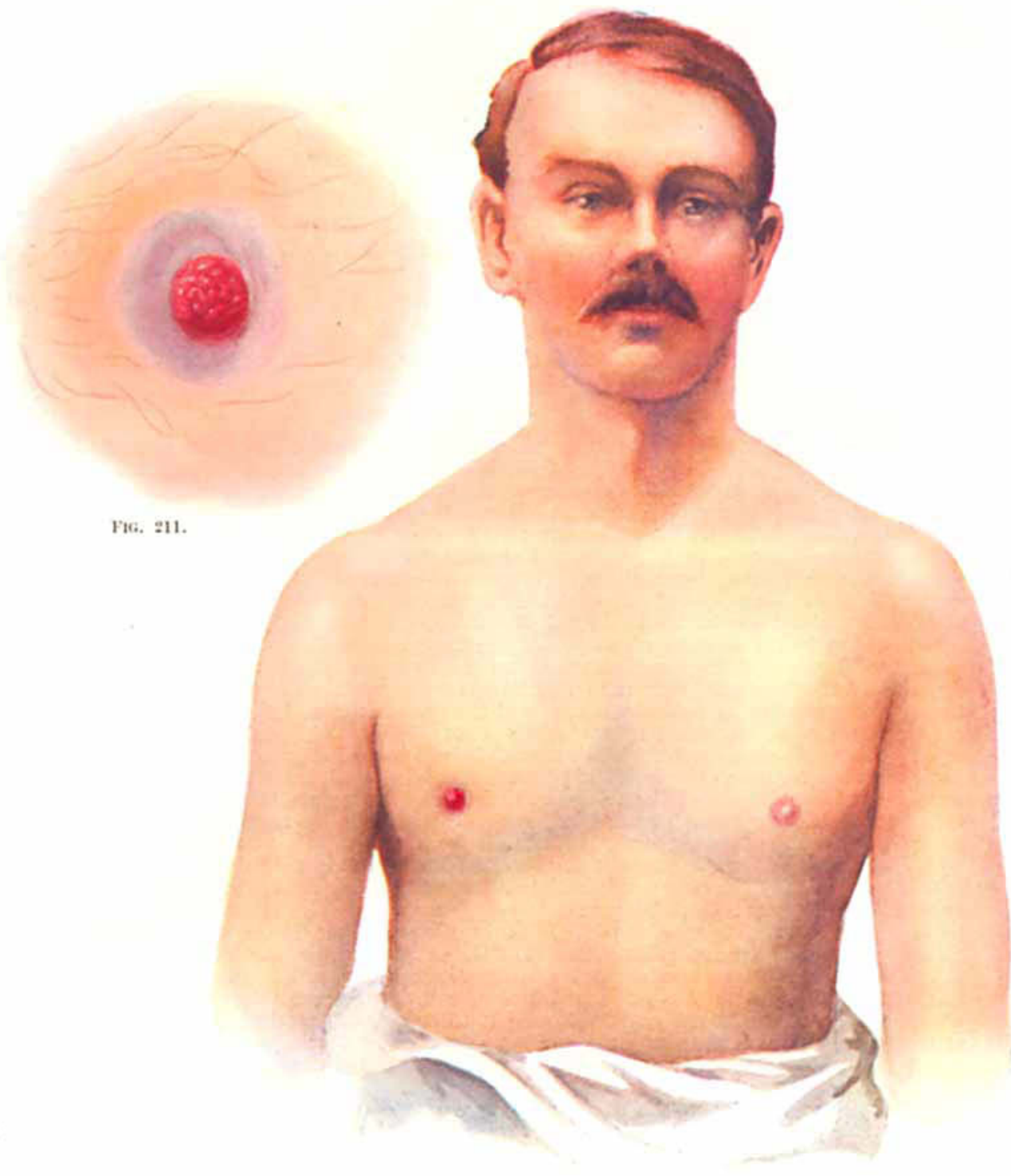

V16 $: 1:$.

Tra. 211.- The right nipgle, natural size. The artist las ratier exaggerated the papillary character of tle surface. It is surrounded by a rather congested zone of areolar pigmentation. Fic. 212.- 'Jihe case of I'aget's disease in a man from which $F$ ig. 210 was derived. The right nipple has been replaced by a fattish, brimht-red papillary surface, betreatì which a small hard growth could be felt. 


\section{PAGET'S DISEASE OF THE NIPPLE}

Had the writer been able to find a single case of definite Paget's disease proved by a thorough examination to be unassociated with cancer, he would not have ventured to put forward the theory that it is a pachydermia due to obstruction by cancerous growth of the lymphatic network of the nipple and areola with consequent compression of the milk-ducts.

The fact that cases of eczema of the nipple, as Mr. Morris has pointed out, do get well and do not subsequently develop cancer, does not in itself invalidate this conclusion, since there is probably no part of the body which escapes from the attacks of ordinary eczema. The nipple and areola form a region particularly liable to irritation.

The foregoing suggestions on the subject of Paget's disease are put forward in a very tentative manner, more as a working hypothesis than as a well-grounded theory.

By 1917 I was sufficiently sure of my ground to present the evidence in the form of a Hunterian Lecture, ${ }^{3}$ for I had found an early case of Paget's disease in which complete permeation of the lymphatic system of the nipple could be demonstrated.

The case is so important that I make no apology for reproducing here the detailed account of it given in my lecture. This course is also necessary to render intelligible the illustrations, which are here published for the first time.

Case 1.-A healthy-looking and well-developed man of 49 , a saddler by trade, was recently sent to me by Dr. J. W. F. Jewell, of Balham. The patient noticed a button-like induration of the right nipple four months before he sought medical advice. There had been no pain and no discharge from the nipple. The nipple was flattened, while the areola, slightly raised above the surrounding surface, presented a bright-red, slightly granular, dry surface, with a few epidermal scales adherent to it (Figs, 211 and 212). Beneath the indurated nipple was a little, hard growth, adherent to the overlying skin, but movable on the fascia beneath. The glands in the right axilla were hard and slightly enlarged.

The growth was removed, together with the pectorals and the axillary glands, and the patient made a good recovery. He remains well three years later.

Histologically, the axillary glands were free from growth. The primary growth was a very cellular carcinoma, sharply marked off from the surrounding tissues. Its infiltrative powers were therefore rather low. On its cutaneous surface, however, it had obtained access to the subareolar lymphatic plexus, and so to the cutaneous lymphatics. These vessels were completely and perfectly injected as by an artificial injection fluid (Fig. 210). In the papillary processes of the dermis the blunt finger-like dilated vessels forming the commencement of the lymphatic system were distended by

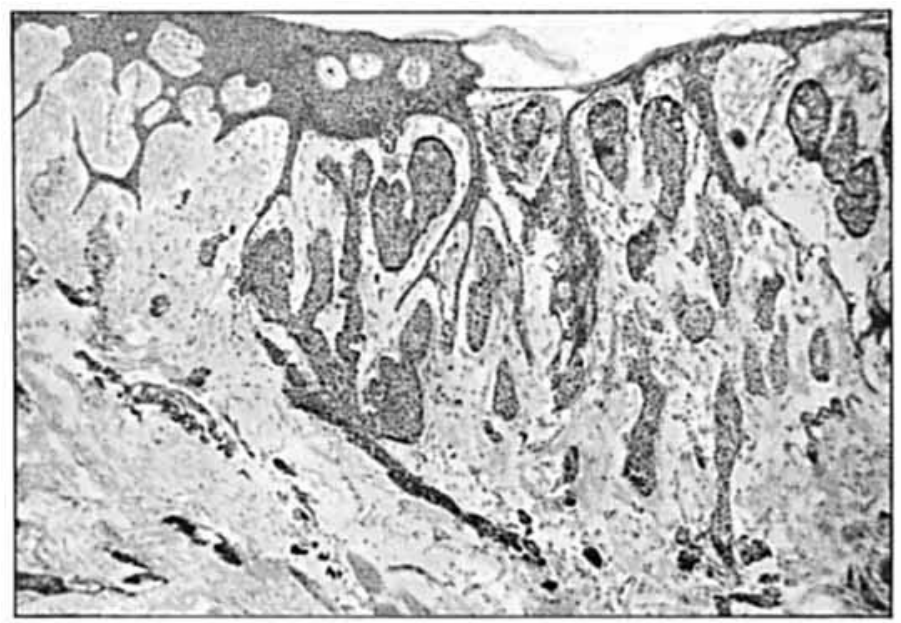

FIG. 213. $(\times 74$.$) A section vertical to the skin surface parallel with$ Fig. 210 through the edge of the are of Paget's disease from the same case. The anatomical arrangement of the permeated lymphatics is here very well shown. A group of the blind finger-like ampulla of origin in the papille are seen uniting to form a narrower lymphatic vessel which runs oblicuely thirough the deeper layer. of the dermis in the direction of the subareolar plexus.

cancer cells exactly like the cells of the growth. The appearance presented is just that of a dilated lacteal in an intestinal villus. Running out of ampullæ of origin are narrower vessels which can be seen in some sections uniting in the superficial layers of the dermis to form vessels of capillary size (Fig. 213), presenting the moniliform dilatations which characterize lymphatic vessels. These vessels take a course vertical or oblique to the 
skin surface, and in the sections are often cut longitudinally and present $Y$-shaped junctions. They run down to and enter the subareolar plexus, which is seen in Fig. 210 lying between the skin and the closely-subjacent breast tissue as a number of vessels, A A A, of larger diameter, cut for the most part transversely, since the section is at right angles to the plane of the plexus.

Serial sections afford clear proof that the longitudinally-cut groups of cancer cells really lie in cylindrical vessels and not in chink-like spaces. The whole arrangement of the vessels stamps them as belonging to the lymphatic, and not the blood-vascular, system.

In horizontal sections the comparison of the cancer-filled spaces in the papillx with the lacteal of an intestinal villus still holds good. In such sections passing just deep to

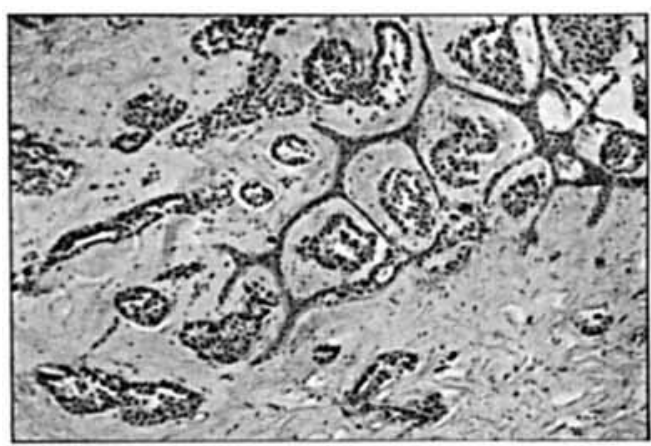

FIG. 214.-( $\times 74$.$) A section, parallel with the surtace of$ the skin through it: payillary layer, from the same case of the skin through its papillary layer, lrom the sane case of and the centro of ressel permeated by cancer cells. the apices of the papillæ (Fig. 214) a circular group of cancer cells occupies the middle of each papilla. This appearance could never be produced by fortuitous infiltration. It indicates with certainty that the cancer cells occupy preformed anatomical spaces, namely, the vessels of origin of the lymphatic system.

A superficial critic might assert that what I have taken to be lymphatic vessels are in truth excretory ducts, passing to open on the surface of the skin. A careful search through all $\mathrm{my}$ sections has shown that a zone of dermis invariably intervenes between the groups of cancer cells and the under surface of the epidermis. Moreover, it is obvious that the apices of the $Y$-shaped unions of the vessels in question are directed away from the skin surface, not towards it as would be the case if they belonged to the excretory apparatus of the skin. Furthermiore, no similar appearance could be detected in numerous sections of the normal nipple.

In regard to the histological details of the specimen, over an area of $2.5 \mathrm{~mm}$. the epidermis is reduced to a layer consisting of a thin sheet of the rete Malpighii, with deeplyextending interpapillary processes as much as $6 \mathrm{~mm}$. in length, i.e., about four times the normal length. Beyond the periphery of this circle is an area of hypertrophied and thickened epidermis forming a circle with an outside diameter of $6 \mathrm{~mm}$. Here also the interpapillary columns of epithelium are much elongated. This is due, not to downgrowth of the epithelium, but to œdematous hypertrophy of the papillæ of the corium, with consequent stretching of the interpapillary columns, for in the centre of the area the interpapillary columns are undergoing atrophy and some of them have disappeared altogether.

Permeation of the skin lymphatics is recognizable over a circle $6.5 \mathrm{~mm}$. in diameter, and extends therefore just a little beyond the point where marked changes in the epithelium cease.

Permeation of the subareolar plexus extends over an area of $10 \mathrm{~mm}$.

These measurements show beneath the circular red area of dermatitis a larger circular erea of permeated lymphatics, and beneath this again a still larger circular area of permeated deep lymphatics belonging to the subareolar plexus.

Now the tendency of Paget's disease to spread centrifugally from its point of origin is a commonplace. It is reasonable to assume that the plane of the superficial tissues in which the affected circle is largest is the plane first affected. 'The relative size of the infection circles measures, in terms of space, the lapse of time since each of the layers was invaded, and therefore the order of their invasion. 'That is to say, the growth at first extends from the breast to the subareolar plexus, and blocks it by permeation. Next, the process 


\section{PAGET'S DISEASE OF THE NIPPLE}

extends to the tributary lymphaties running from the skin to the subareolar plexus. Lastly, as a result of lymph stasis from permeation, œedematous hypertrophy of the papillæ is seen and nutrition fails in an area of the overlying epidermis.

It is possible to conceive of the process reversed, and to assume that it spreads more rapidly once it reaches the subareolar plexus. But the permeation of the lymphatics of the dermis cannot possibly be the result of the changes in the epidermis. For the cells contained in these permeated lymphatics are not cutaneous cells, but cells originating from the mammary epithelium.

For this reason I am entitled to conclude that the changes in the epidermis are secondary to the permeation of the dermal lymphatics, that the 'eczema' is secondary to a pre-existing carcinoma.

A third possibility remains, that the dermatitis and the permeation of the dermal lymphatics are independent events. If so, how comes it that the areas are concentric ? At either edge of the circles permeation of the dermal lymphatics is seen extending under cedematous skin just beyond the edge of the eczematous area. My critics must find a reason for this striking fact. The only natural explanation of it is that the dermatitis is a consequence of the subjacent permeation.

It may be asked why other observers have failed to find evidence of permeation in Paget's disease. The assumption inherent in this question is incorrect, for other observers have seen the appearances of permeation, but have misinterpreted them. Thus Wickham gives an illustration which resembles my case very closely, and is reproduced as Fig. 215. Permeation is seen spreading beneath normal epithelium, while beneath the eczematous area are permeated lymphatics, distended by cancer cells, running vertically upwards into the papillary region of the dermis. Wickham seems to have considered that these epithelial groups were down-growing processes of the epidermis; but an inspection of his plate shows that the largest of these masses, though in close

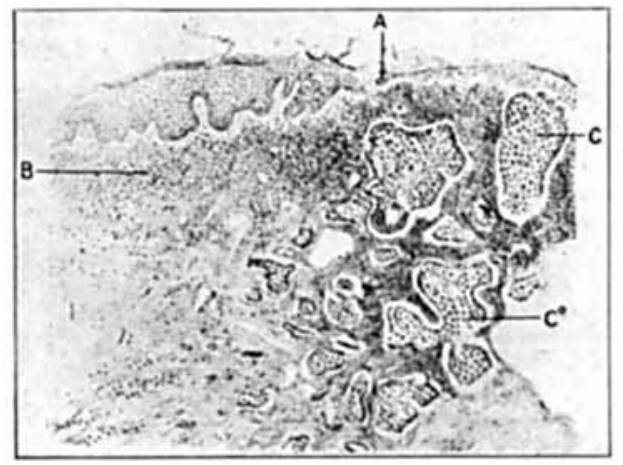

FI(1. 215.--From Wickham, Maladie de Past, 1890, Plate 1I, Fig. 11. Coupe d'un noyau cancereux di Plate 11, Fig. 11. Coupe dun noya cancereux di mamelon. (A) Epiderme exuceree dasis lequel on rouve des psorospermies. (B) Zone inflammatoire. (C C) Lobes epitheliaus. It will be seen that the figure shows permeation of the dermal lymphaties by the cell of the growth beneath. It is in fact exactly similar to Fig. 210. Its appearances were misinterpreted by Wickham, who apparently thought tlue masses $\mathrm{C} C$ consisted of epithelium of cutaneous orjyin.

touch with the deep surface of the epidermis, is defined with absolute sharpness from it.

Duhring and Wile found, in the middle and lower layers of the corium, alveoli of varying size, some of them linear, containing typical carcinomatous epithelium. These 'alveoli,' which were doubtless permeated lymphatics, were present in both the cases they examined.

In three or four cases of Paget's disease in which dermal permeation could not be shown, I have nevertheless found permeated lymphaties in the subareolar plexus (Figs. $216,217)$.

It may be objected that if dermal permeation (Fig. 210) is so rare that it has only been shown in two cases, Wickham's and my own, it cannot be a normal or constant event in the development of Paget's disease. There may be truth in this argument, for obviously complete permeation of the subareolar plexus will suffice to dam completely the lymph stream from the dermal lymphatics without any actual extension of permeation to the dermal lymphatics themselves. The effects of a dam across a river extend up-stream for a long way.

It is not necessary, in order to establish the conditions for the onset of Paget's disease, that permeation should extend right into the lymphatics of origin in the dermal papillæ. The obstacle to lymph return from the skin may be equally insuperable whether the block 
is situated in the lymphatics of origin of the dermal papillæ or in the subareolar plexus into which they drain. The microscopical appearances will, however, differ. Those produced by permeation of the lymphatics of origin are striking, as Fig. 210 shows, while permeation of the subareolar plexus may easily be overlooked or misinterpreted. It is not less significant and much more frequent.

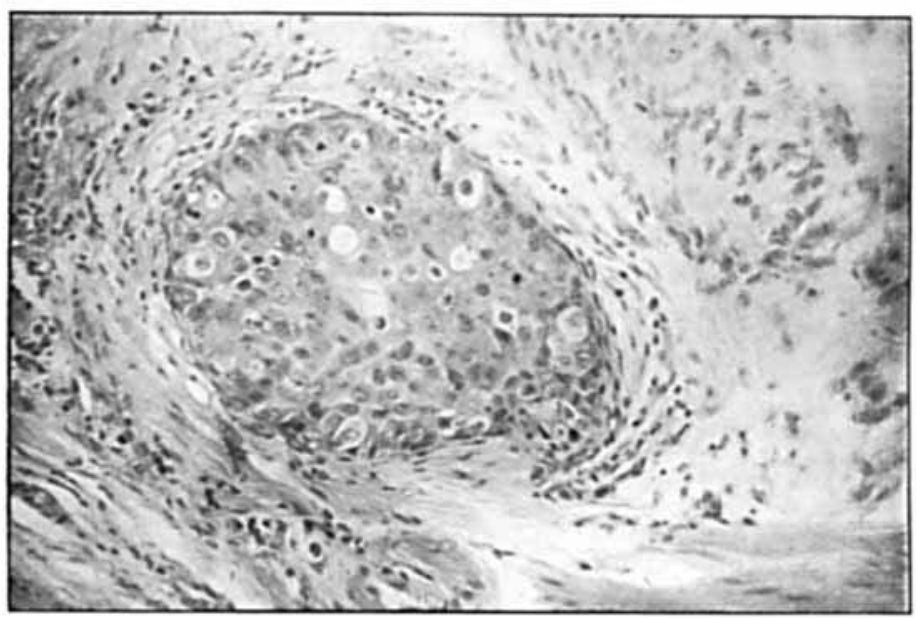

FIG. 216. - ( $\times 134$.$) A partially fibrosed permeated lymphatic from the deeper layer of the dermis in a case of P$ arget's disease. A group of degenerate cancer cells is seen, surrounded by a sheath of newly-formed fibrous tissue. Such permeated lymphatics can frequently be demonstrated in the deeper lavers of the dermis. On the contrary, it is very rare to be able to demonstrate such complete permeation of the lymphatics as is seen in Fig. 210.

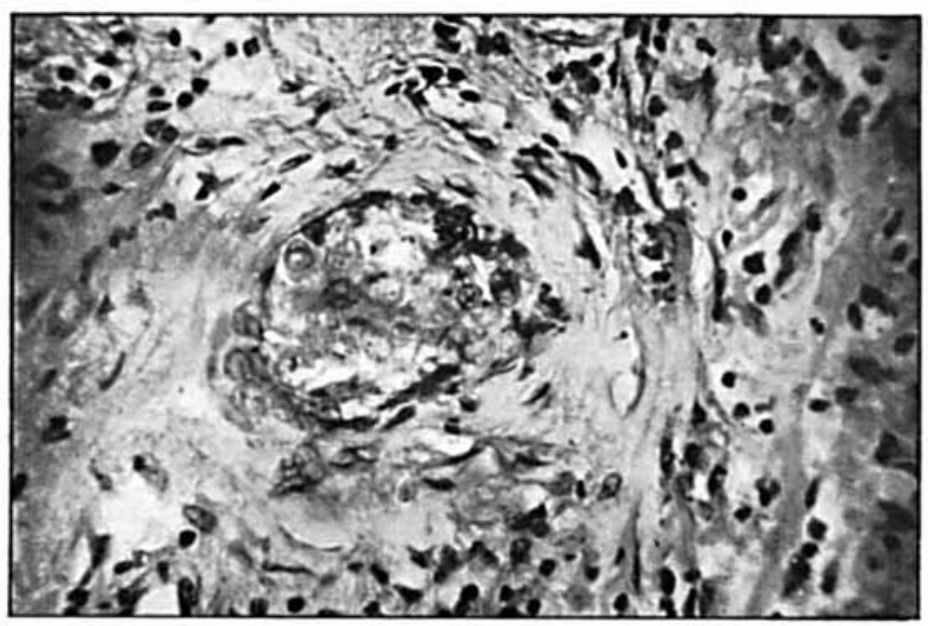

FiG. 217.-( $(306)$. A higher-power photograph of a similar permeated lymphatic from the deeper layer of the dermis, showing the characters of the degenerate cancer cells, and of the zone of fibrous tissue which is strangling them.

It is probable, however, in my opinion, that dermal permeation could be demonstrated in most cases of Paget's disease if it were sought for at the right moment. I have shown that a permeated lymphatic is a fugitive phenomenon which soon undergoes fibrosis and destruction, leaving a legacy of permanent lymphatic obstruction. One would not expect to find flame in a region swept months or years previously by a forest fire, nor must one expect to find permeated dermal lymphatics in chronic cases of Paget's disease. 


\section{PAGET'S DISEASE OF THE NIPPLE}

Anatomy of the Cutaneous Lymphatics. - It is essential for the proper understanding of Paget's disease to know something of the anatomy of the cutaneous lymphatics.

In this, as in other branches of histological lymphatic anatomy, Sappey is an unsafe guide, for his methods of injection, excellent as they were for the naked eye, did not permit him to cut histological sections.

A brief description of the lymphatics of the skin of the auricle of the white rat is given by Ranvier ${ }^{4}:-$

The lymphatic capillaries form simple or composite culs de sac. They do not reach the epidermis, but are separated from it by a distance of $1 \mathrm{~mm}$. Their diameter is relatively considerable, and has an average of $\cdot 04 \mathrm{~mm}$.; it may attain $.05 \mathrm{~mm}$. These are large figures for capillary vessels, and much exceed those of the blood capillaries. No trace could be seen of the supposed plasmatic canals, juice canals, or canaliculi, which, according to certain purely theoretical ideas, form the origin of the lymphatic system.

Upon these observations Ranvier gave up his former belief in the existence of direct communications between the connective-tissue spaces and the interior of the lymphatic vessels.

His account is borne out entirely by the observations I have made upon the lymphatics of human skin. Using soluble Prussian blue as an injection fluid, I have been able to demonstrate that the lymphatics of the skin originate as blind finger-like culs de sac in the dermal papillæ. As in the rat, the lymphatics of origin are separated by a thin Iayer of dermal fibrous tissue from the deep surface of the epidermis. The finger-like processes are continued into narrower vessels, several of which unite together in the deeper layers of the dermis to form a collecting vessel which passes more or less vertically through the sub-

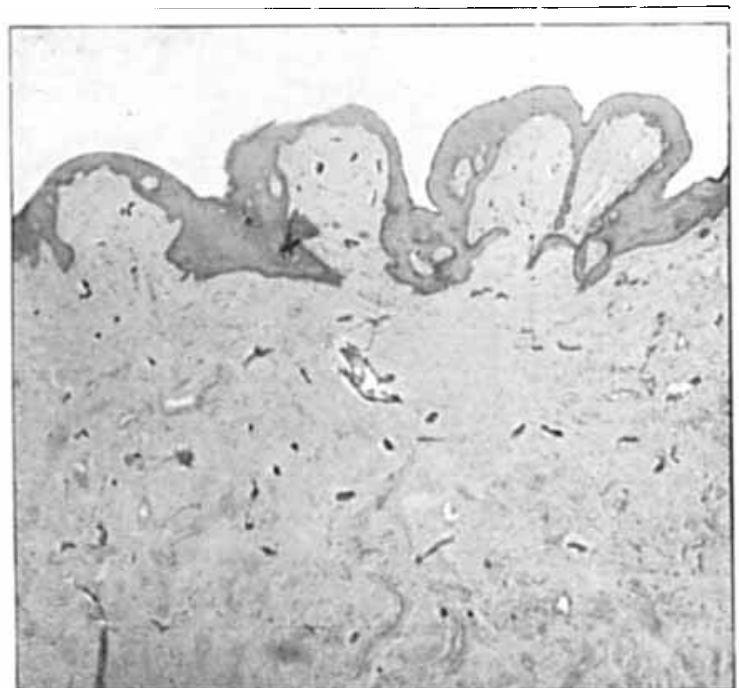

FIG. 218. - A section ( $\times 20$ ) of the skin of the normal breast, showing the cutaneous lymphatics injected by soluble Prussian blue. The origiti of the lymphatic vessels as blind sacs in the cutaneous papilla can be seen. cutaneous fat to join the fascial plexus (see Fig. 218).

Summary of Conclusions.-A carcinoma starts in the smaller ducts of the breast, perhaps exceptionally from the acini or the larger ducts. Usually, without producing a palpable tumour, it permeates the breast lymphaties widely. The rich plexus of lymphatic vessels around the ducts forms an especially easy and convenient channel for permeation, and the lymphatic block extends along them to the subareolar plexus beneath the nipple.

The cutaneous lymphatics about the nipple are now dammed up so that lymph cannot return from them. Later they are themselves permeated, but possibly this is not always the case. At this stage, and before any lump has appeared in the breast, the skin of the nipple and the mucosa of the ducts begin to show changes dependent upon lymphatic obstruction. The epithelium shows disintegration and degeneration of its superficial layers, with proliferation of the deeper layers. These changes are nutritional and nonmalignant. The dermis becomes thickened by solid lymphatic odema. The lymphatics of origin in the superficial layer of the dermis are filled with cancer cells, which are also to be seen in the lymphatics of the subareolar plexus. The permeated lymphatics now 
undergo the usual process of perilymphatic fibrosis ; they become surrounded by aggregations of inflammatory round cells, and later by young fibrous tissue which contracts upon and destroys the included cancer cells. In most cases, at the time the disease is removed

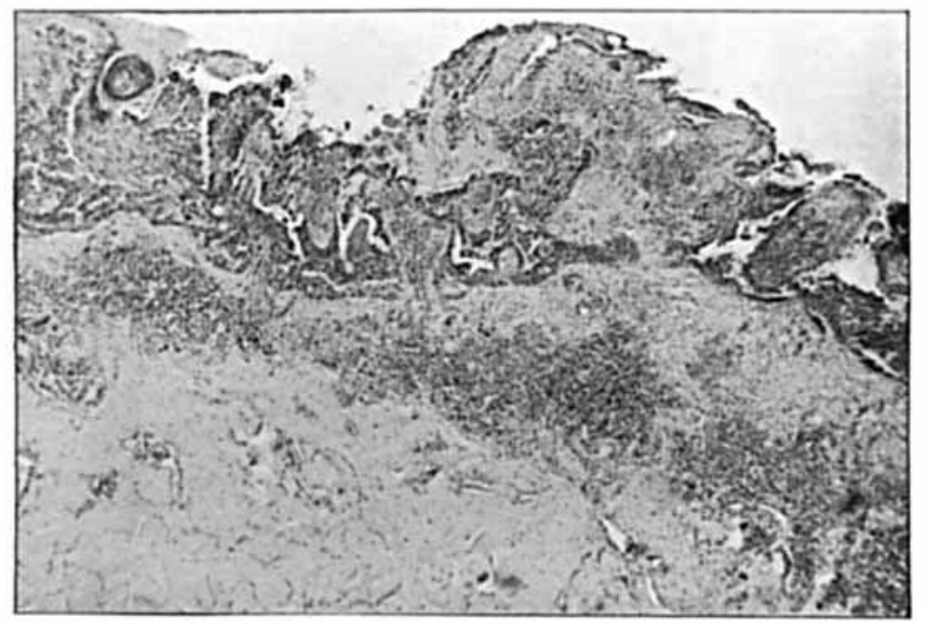

Wt, 219_- $(\times 37$.$) Paget's disease. In this section the hypertrophied papille of the dcrmis are beginning to undergo$ atrophy from lateral compression. The epidermis is $i_{11}$ an advanced stage of disorranization. The typical band of round-celled infiltration in the superficial layer of the dermis is well defined. There is no present evidence of perineation.

the destruction of the cancer cells has been consummated, and there is seen merely a band of round-celled infiltration in the superficial dermis, while in the deeper dermis perivascular aggregations of round cells indicate the destruction of the lymphatics which are known

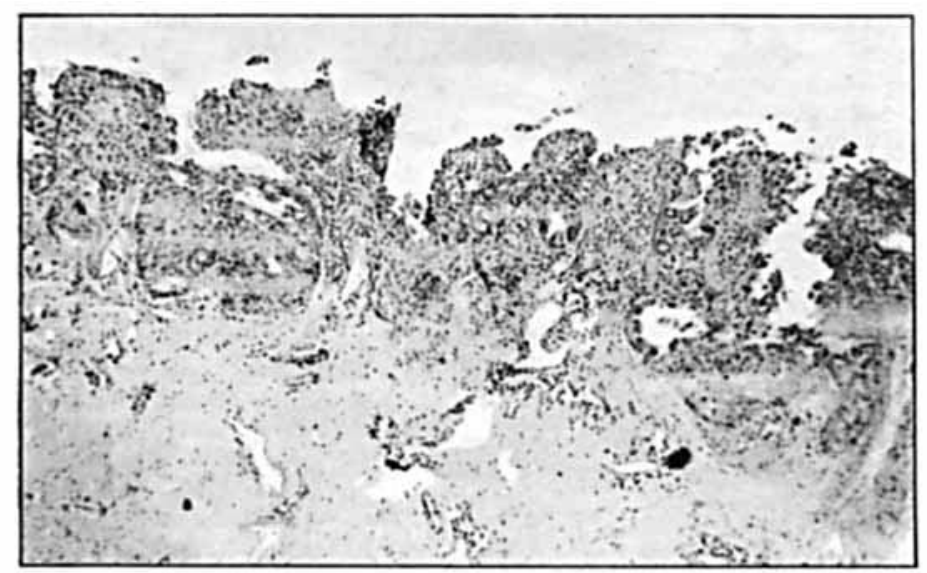

114. 220.- $(\times 44$.$) This section shows a monent in Paget's disease intermediate between the hypertrophic and$ atrophic stages. The papilla are still much elongated and broadenerl by lymphatio cedema, and have not undergone fibrosis. The overlying epithelium is undergoing rapid destruetion and exfoliation, and is reduced to a layer two or three cells thick. The band of round-celled infiltration in the superficial part of the derinis is not so definite as ustal.

to accompany the blood-vessels in this layer. In other and later cases organization into fibrous tissue is complete, round cells have disappeared, the papilla have been destroyed by the fibrous contraction which has taken place in them, and nothing remains to show that the lymphatic vessels of the dermis have been obliterated and replaced by fibrous 


\section{PAGET'S DISEASE OF THE NIPPLE}

cords, save and except the persistent changes in the epithelium and the cdematous thickening of the dermis (Figs. 219, 220, 221).

In regard to the changes in the large ducts, these are evidently similar in nature to

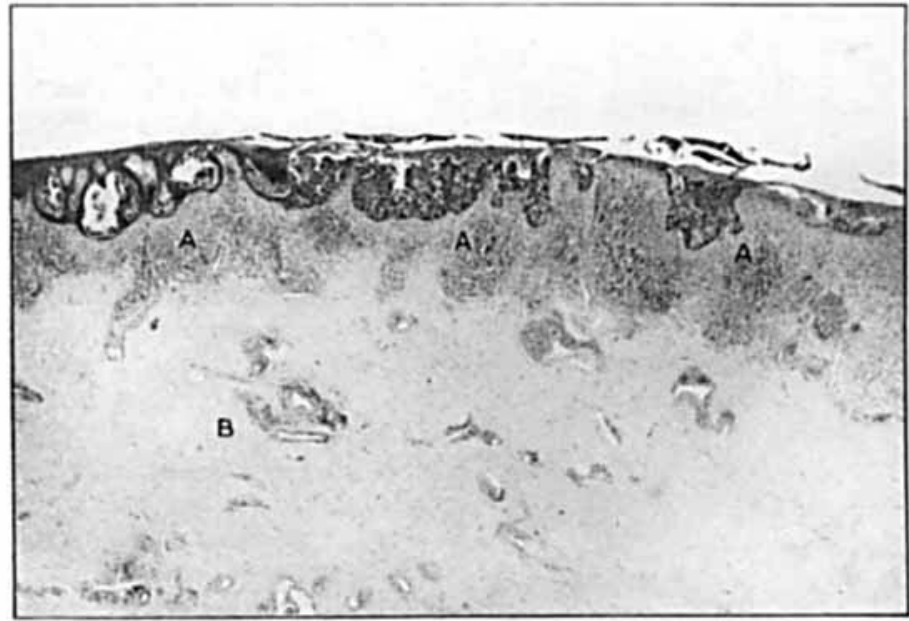

Fic. 221.-A section ( $\times 23)$ through an area of Paget's eczema. On the right-hand side the epitheljum is on the point of disappearing altogether On the left of the figure the interpapillary columing of epithelium show advanced degeneration, and their certral eells have undergone liquefaction, producing larwe vacuoles. The papilia themselves, under the tion, al pressure thus produced, have underoue almost complete atroph

A band of round-celled infiltration (A A A) is seen occupying the superficial layer of the dermis. This layer corresponds with the zone of origin of the lvmphatic vessels of the skin. The rest of the dermis, extending to the lower edge of the figure, is much thickened, but is otherwise normal except for occasional lymphatic vessels blocked by round-celled infiltration, such as the one seen at $\mathbf{B}$.

In this scction lymphatics permeated by cancer cells are absent, having probably undergone complete fibrosis.

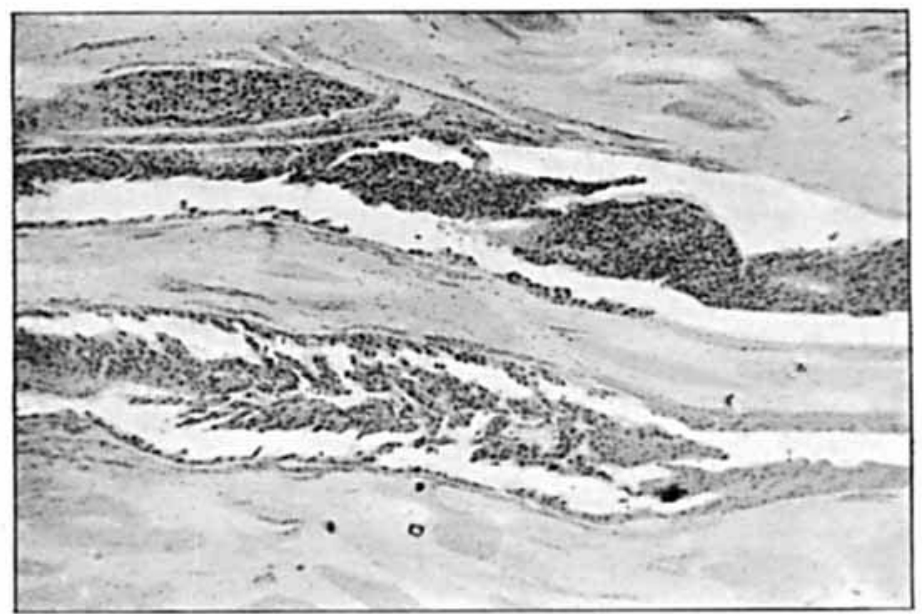

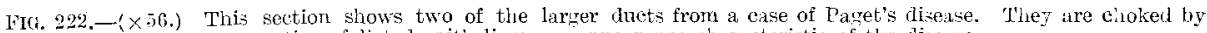
necrotic exfoliated erithelium, an appearance characteristic of the disease.

those found on the surface of the nipple, and they depend upon the same cause, namely, lymphatic obstruction from permeation and subsequent fibrosis. The only difference is that the shed epithelium cannot get away, and remains in situ, plugging and distending the ducts with a degenerate mass of débris (Fig. 222). Lastly, even in the rare cases where 
no carcinoma has made its appearance, though the Paget's disease has lasted many years,

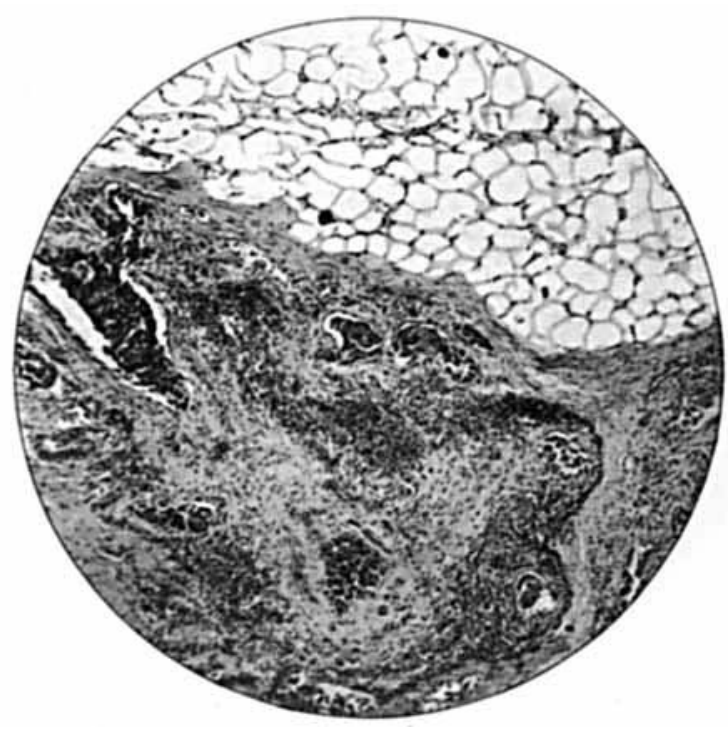

FI(4. 223.-( $\times 47$.) From the case of Mrs. L-..-, age 68, with early Paget's disease, showing the extensive fibrosi around the ducts of the breast, with destruction of the fat lobules. Embedded in the adventitious fibrous tiscue are irregular groups of targe deeply-staining polymorphic epithelial cells, jndistinguishable from the cells of a carcinoma. At one or two points appearances suggesting infiltration are see:?.

it is probable that an atrophic scirrhus, which may have undergone partial or complete cure, preceded the onset of the Paget's disease. But the possibility that the lymphatic obstruction in such cases is of inflammatory origin, and due to a chronic lymphangitis, cannot be altogether excluded.

A Test Case.-A recent case which came under my care afforded an opportunity of testing the conclusion that Paget's eczema of the nipple results from a pre-existing carcinoma of the atrophic type. The eczema had existed only for six months, and no lump was present in the breast, nor were the glands enlarged. The only indications of carcinoma, apart from eczema, were that the right breast was slightly drawn up, so that its nipple was on a higher level than the left. There was also a slight general shrinkage of the right breast. The following are the notes of the case.

Case 2.-Mrs. I., age 68, consulted Dr. Carmichael, of Wandsworth, for eczema of the right nipple; six months previously she noticed the formation of a little scab on the nipple which dropped off, leaving the nipple sore and painful. She used various ointments, but the scabs continued to re-form and drop off. While in Scotland, in October, 1918, she consulted a lady doctor, who diagnosed either Paget's disease or eczema. 'There had not been much discharge from the nipple, but when the top came off, serum or blood oozed out. She has suffered from psoriasis appearing at the back of the elbows for ten years. On examination $I$ found the right nipple flattened and slightly discoloured, but not of the typical bright red of Paget's disease. Situated rather eccentrically towards the upper and outer part of the nipple was a flat papyraceous induration or plaque. In the upper and outer quadrant of the breast--the part corresponding with the little plaque on the nipple-there was slight mastitic induration. The left nipple was normal, and no lump could be felt in the left breast. There was no adhesion to skin or fascia. My conclusions on the case were embodied in a letter to the patient's doctor in which I said that, although there was no lump in the breast, there was a distinct suspicion

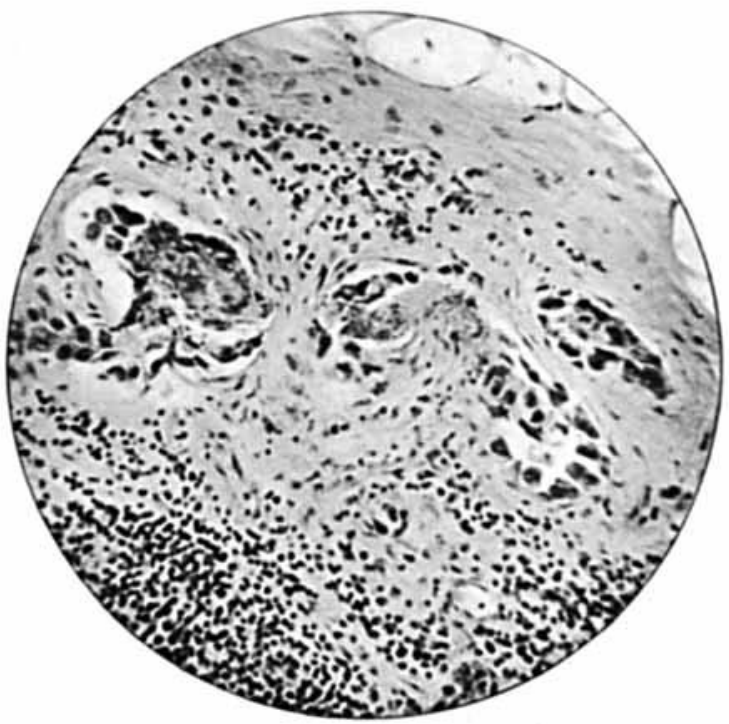

FIt. 224, - ( $\times 180$.) A portion of the preceding figure highly magnified, showing appearances which sugrest incipient infiltrdtion. 'The condition appears to be an atrophie eareinoma vigorously restrained by active stroma-formation. 


\section{PAGET'S DISEASE OF THE NIPPLE}

of carcinoma quite apart from the condition of the nipple, since the whole breast was elevated as compared with the opposite side. The clinical history of the eczematous area of the nipple was that of commencing Paget's disease, although there was no coloration such as is characteristic of the disease in its developed state. I believed there must be an early carcinoma in the breast, although there were no glands in the axilla; that in any event the breast was a dangerous one, and, as it could be removed with very little risk to the patient, I strongly advised that this should be done.

The patient accepted the advice to have the breast removed, and made a good recovery from the operation.

I had the opportunity of examining the section of the nipple, which showed the apperrance of early Paget's disease, especially a vacuolation and disintegration of the epidermis, with disappearance of the interpapillary cell columns and a zone of round-celled infiltration in the superficial layers of the dermis. There appeared to be dilatetion of the lymphatics of the nipple. The section from the indurated area of the breast showed ducts filled up by epithelium and surrounded by fibrous tissue and by dense masses of round-celled infiltration. There was marked proliferation of the smaller ducts, and in the fibrous tissue there were found numerous groups of epithelium varying in size, and mostly surrounded by concentric laminæ of old fibrous tissue or by zones of inflammatory round cells. Many of these groups showed greater or less cell-degeneration; the cells composing them were large, irregular, and deeply staining, and indistinguishable from the cells of a carcinoma. In some places the groups of epithelial cells appeared to be free in the connective tissue spaces (Figs. 223, 224), but nowhere could any large mess of clearly cancerous epithelium be seen. My reading of these appearances was that one had to deal with a cancer of atrophic type to which the inflammatory reaction of the tissues was opposing a stout resistance. I believe that many of the groups of epithelium represented permeated lymphatics in various stages of fibrosis, but $I$ freely admit that this opinion is not susceptible of demonstration. Wishing to obtain an independent opinion on the specimen, I sent it to Dr. Ernest Shaw without giving any indication of its origin. In reply he wrote to me as follows: "This section shows marked inflammatory changes, i.e., plenty of small, roundcelled infiltration and overgrowth of the epithelium. Although the epithelial cells are large, irregular, and numerous, they are enclosed by well-marked fibrous rings. In one place this ring is not so definite, and therefore suggests malignant change. It is probable there is malignant growth in the neighbourhood of this section which possibly passes just beyond its periphery."

A consideration of the evidence I have detailed will, I think, convince the reader that in this case, although the eczema had only lasted for six months, there was an atrophic carcinoma of the breast which had excited violent inflammatory reactions in the organ suflicient to obstruct many of the lymphaties of the nipple. In my view this lymphatic obstruction of the nipple was the cause of the eczema which drew attention to the breast. The case supplies evidence, as strong as is likely from the nature of things to be obtained, that, even in the earliest stage of Paget's disease, carcinoma is already present. If, as I hope, the practice of early removal of the breast for Paget's disease becomes general, further evidence upon this point will shortly be to hand.

It cannot escape the reader's notice how closely the microscopic appearances in this case resemble those present in Barling's case already referred to. In both there was evidence of a chronic catarrh of the larger ducts, with much surrounding inflammatory infiltration and fibrosis, and this inflammatory process probably preceded and was the cause of the duct carcinoma which supervened later.

It may, of course, be maintained that the chronic inflammation of the ducts, and not the carcinoma, was the cause of the lymphatic obstruction which produced Paget's eczema of the nipple. Such a view is difficult to disprove, but it is almost certain that the chronic inflammation of the ducts was of a date long prior to the eczema. The latter condition had been present in both cases only six months.

The probabilities all favour the view that the lymphatic obstruction which is the cause of Paget's eczema results from neoplastic and not from mere inflammatory obstruction of the lymphatics. 


\section{THE BRITISH JOURNAL OF SURGERY}

Even if in rare cases it is possible that the eczema results from a block in the lymphatics of inflammatory origin, it is certain that this form of chronic inflammation of the ducts is a very dangerous condition which almost invariably leads to carcinoma. Sir James Paget acknowledged that in all cases in which he excised the eczematous nipple a carcinoma subsequently appeared in the breast. Early and complete removal of the breast is therefore demanded whatever the view adopted as to the order in time of the eczema and the carcinoma.

\section{REFERENCES.}

1 Deaver, McFarland, and Herman, The Breast, its Anomalies, its Diseases, and their Treatment. Heinemann, 1918

2 Barina, "Carcinoma of Breast following Eczema of Nipple," Trans. Path. Soc., vol, xli, p. 219.

3 Handeey, Lancet, 1917, April 7.

4 Ranvier, Comptes rendus de l'Académie des Sciences, 1835, vol. cxxi. 


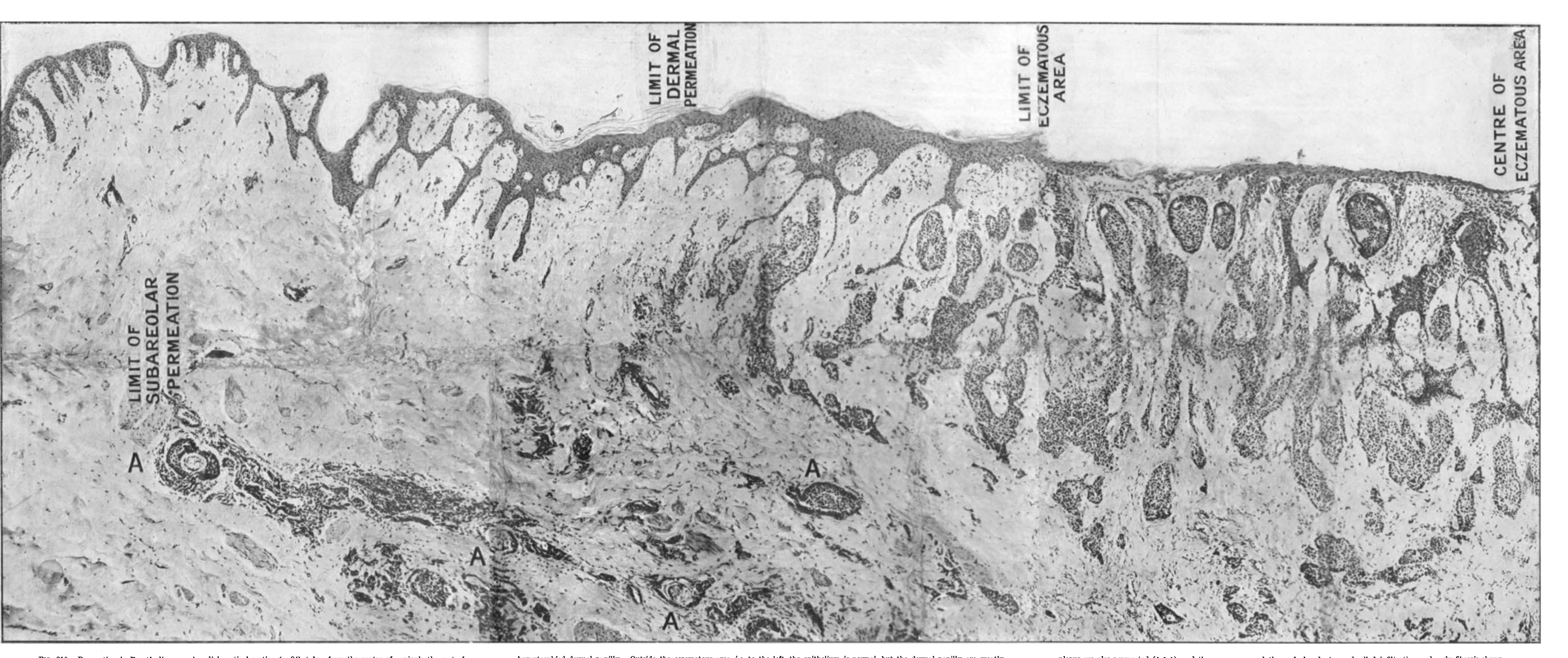

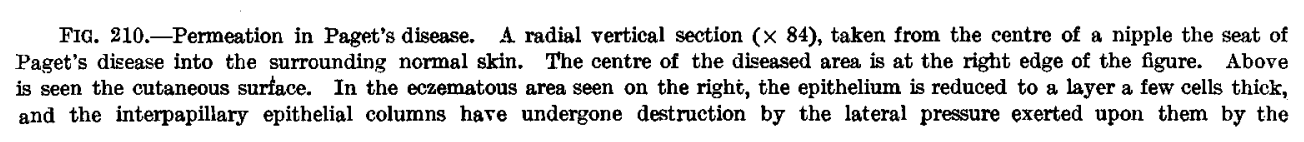

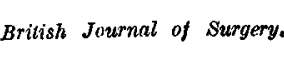

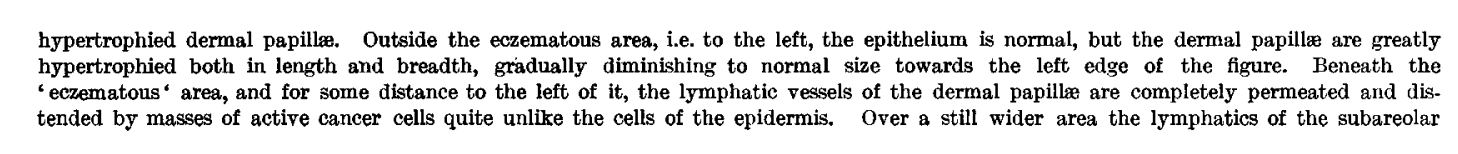

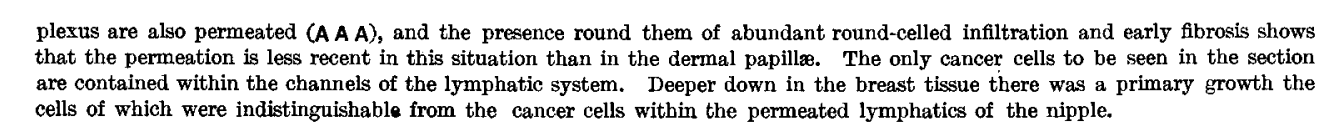

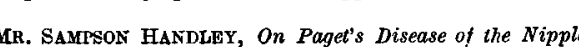

